\title{
Confidential
}

\section{Poultry Litter Gasification in a Fluidized Bed Reactor: Effects of Gasifying Agent and Limestone Addition}

\author{
L.P.L.M. Rabou \\ L.E. Fryda \\ D.S. Pandey (Univ. of Limerick) \\ M. Kwapinska (Univ. of Limerick) \\ A. Gómez-Barea (Univ. of Seville) \\ A. Horvat (Univ. of Limerick) \\ J.J. Leahy (Univ. of Limerick) \\ W. Kwapinski (Univ. of Limerick)
} June 2016 ECN-W--16-010 


\title{
Poultry Litter Gasification in a Fluidized Bed Reactor: Effects of Gasifying Agent and Limestone Addition
}

\author{
Daya Shankar Pandey, ${ }^{\dagger}$ Marzena Kwapinska, ${ }^{*}{ }^{\S}$ Alberto Gómez-Barea, ${ }^{\perp}$ Alen Horvat, ${ }^{\dagger}$ Lydia E. Fryda, ${ }^{\dagger}$ \\ Luc P. L. M. Rabou, James J. Leahy, ${ }^{\dagger}$ and Witold Kwapinski ${ }^{\dagger}$ \\ ${ }^{\dagger}$ Carbolea Research Group, Department of Chemical and Environmental Sciences and ${ }^{\S}$ Technology Centre for Biorefining \& \\ Biofuels, University of Limerick, Limerick, Ireland \\ ${ }^{\perp}$ Chemical and Environmental Engineering Department, Escuela Técnica Superior de Ingeniería, University of Seville, Camino de los \\ Descubrimientos s/n, 41092 Seville, Spain \\ "Energy Research Centre of The Netherlands (ECN), Biomass \& Energy Efficiency, Petten, The Netherlands
}

\begin{abstract}
Air and air-steam gasification of poultry litter was experimentally studied in a laboratory scale bubbling fluidized bed gasifier at atmospheric pressure using silica sand as the bed material. The effects of equivalence ratio (ER), gasifier temperature, steam-to-biomass ratio (SBR), and addition of limestone blended with the poultry litter, on product gas species yields and process efficiency, are discussed. The optimum conditions (maximum carbon conversion, gas yield, heating value, and cold gas efficiency) were achieved at an ER 0.25 and $800{ }^{\circ} \mathrm{C}$, using air $(\mathrm{SBR}=0)$ and poultry litter blended with $8 \%$ w/w limestone, yielding a product gas with a lower heating value (LHV) of $4.52 \mathrm{MJ} / \mathrm{Nm}^{3}$ and an average product gas composition (dry basis) of $\mathrm{H}_{2}: 10.78 \%, \mathrm{CO}: 9.38 \%, \mathrm{CH}_{4}: 2.61$, and $\mathrm{CO}_{2}: 13.13$. Under these optimum processing conditions, the cold gas efficiency, carbon conversion efficiency, and hydrogen conversion efficiency were 89, 73, and 43\% respectively. The reported $\mathrm{NH}_{3}$ measurement at an ER of 0.28 and $750{ }^{\circ} \mathrm{C}$ is $2.7 \%$ (equivalent to $19,300 \mathrm{mg} / \mathrm{Nm}^{3}$ ) with $14.7 \mathrm{mg} / \mathrm{Nm}^{3}$ of $\mathrm{HCl}_{\mathrm{observed} \mathrm{as}}$ the dry product gas. High temperature and steam injection favor production of $\mathrm{CO}$ and $\mathrm{H}_{2}$, while their effect on $\mathrm{CH}_{4}$ was almost negligible. It is demonstrated that poultry litter can be gasified by blending with limestone, making it possible to overcome the fluidization problems caused by the mineral composition of poultry litter ash (high $\mathrm{K}$ and $\mathrm{P}$ content), yielding a gas with a similar heating value compared to gasifying without limestone addition, but with a significantly lower tar content.
\end{abstract}

\section{INTRODUCTION}

Livestock production is among the most rapidly growing sectors of the agricultural economy driven primarily by growing demand for animal protein. New livestock production has shifted progressively from ruminants such as cattle to pigs and poultry, which are forecast to grow by more than $60 \%$ by 2030 , the vast majority of which will occur in intensive farming units. ${ }^{1}$ Intensive livestock production, while more efficient than traditional farming practices, poses significant challenges in terms of its effects on the natural environment due to the accumulation of large quantities of waste with estimates of 1.4 billion tonnes ${ }^{2}$ of manure in EU states. This accumulation of manure often results in its over application as a nutrient source for crops giving rise to social and environmental problems, such as odors, pathogens, and eutrophication of surface waters. Within the EU, the livestock industry has to adapt to an EU regulatory framework including the Nitrates (91/676/EEC) and Water (2000/60/EC) Directives which demand improved environmental performance. ${ }^{3}$

Waste management of organic streams can effectively be achieved with thermal recycling (combustion, pyrolysis, gasification, liquefaction) and biochemical conversion (digestion, fermentation), with the choice of conversion process dependent on the feedstock properties and availability, the desired end products, the economic value, and relevant environmental standards. The main advantages of thermal processes are their ability to convert the waste to a sterile material with a significant reduction in volume by $80-95 \%$ (depending on feedstock composition and treatment technologies $)^{4,5}$ and to recover energy either directly as heat or as energy carriers. ${ }^{6}$

Poultry litter is a heterogeneous fuel, composed of bedding material, excreta, waste feed, and feathers. ${ }^{7}$ In the past, several reviews ${ }^{8,9}$ explored the advances in disposal technology for poultry litter and for producing bioenergy from livestock waste. These studies clearly indicated that thermochemical conversion processes have capabilities to convert animal byproducts into combustible gases, bio-oils, and biochar (soil amender/ fertilizer). Most of the published research studies on poultry litter have focused on combustion, cocombustion with coal, and fixed bed (updraft and downdraft) gasification. Poultry litter combustors (incinerators) are currently used for electricity production and ash recycling in the UK, the United States, and The Netherlands. ${ }^{10}$ Thermal gasification provides some advantages and greater flexibility over direct combustion as it produces a product syngas that can either be used in gas engines or boilers for heat and electricity production. Additionally the gas can be cleaned before burning, opening the potential processing of wastes and dirty biomass feedstocks. For small and medium scale systems, gasification has emerged as an alternative viable technology with higher energy conversion efficiency to electricity than traditional combustion

Received: January 11, 2016

Revised: March 14, 2016

Published: March 18, 2016 
processes, while complying with present EU's emission standards. ${ }^{11}$ Solid byproducts from the gasifier can be used on agricultural lands to improve the soil permeability and reduce nutrient runoff. However, leachate tests have yet to be performed to understand the fate of residues and their effect on contaminating surface and groundwater. The European Parliament has adopted the animal byproduct Regulation (1069/ 2009/EU) supplemented with Regulation (142/2011/EU), to pave the way for processing animal byproducts locally for nutrient recycling while producing bioenergy.

Gasification is a thermochemical conversion process which converts carbonaceous material into a useful gaseous product at elevated temperature in the presence of a limited amount of air. Thermal gasification can be used for the conversion of a wide range of fuels (wood, coal, etc.) as well as low calorific value feedstocks such as animal byproducts and organic wastes. Gasification is a complex thermochemical process involving drying, devolatilization, partial oxidation, and reforming of both gaseous and solid carbon species. Gasification can be undertaken either in fixed/moving bed (updraft and downdraft configurations or some variation of these), fluidized bed, or entrained flow reactors. ${ }^{12}$

Several fixed bed gasification studies on feedlot manure and poultry litter have been performed over the past decade. Poultry litter gasification has been carried out in small-scale fixed bed gasifiers in order to recover energy ${ }^{13-17}$ to reduce odor emission and nutrient runoff as well curtail land spreading. In contrast, relatively few attempts have been made to gasify animal manure in a fluidized bed gasifier, mainly due to the higher ash content compared to other biomass. Raman et al. ${ }^{18}$ gasified dried swine manure in a fluidized bed gasifier using air as a fluidizing medium and silica sand as the bed material. This study concluded that both the product gas yield and energy recovery increased with temperature. Recently, poultry waste was gasified in a prepilot scale atmospheric air-blown fluidized bed gasifier to investigate the behavior of ash composition, ${ }^{19}$ and the authors concluded that while it is a feasible process, proper fuel characterization is essential due to the feedstock heterogeneity and the risk of sintering and agglomeration arising from some ash constituents.

The presence of a higher fraction of low melting compounds $(\mathrm{K}, \mathrm{Na})$ and a smaller amount of higher melting species $(\mathrm{Ca}$, $\mathrm{Mg}$ ) in the feedstock ash can give rise to ash melting and agglomeration in the bed. ${ }^{20,21}$ In particular, low $\mathrm{CaO}$ content in the fuel ash is found to increase the likelihood of ash melting. ${ }^{20}$ Billen et al. ${ }^{22}$ concluded that the higher amount of phosphorus (P) present in poultry litter can lead to problems with bed defluidisation, and they suggested that calcite addition might lower the risk of bed agglomeration during fluidized bed combustion of poultry litter. Prevention or mitigation of defluidisation may be achieved by mixing limestone with poultry litter in the fuel intake. This provides calcium for the reaction with phosphorus, forming a high melting temperature calcium phosphate which coats onto the silica particles preventing reaction between potassium phosphate and silica. ${ }^{23}$ Fryda et al. $^{24}$ tested the agglomeration tendency of olive bagasse in an atmospheric fluidized bed gasifier with quartz sand $\left(\mathrm{SiO}_{2}\right.$ with a mean particle size $\left.0.27 \mathrm{~mm}\right)$ and olivine. They concluded that tests with olivine resisted defluidisation at higher temperature because $\mathrm{MgO}$ interacts with the fuel ash and elevates the melting temperature. Walawender et al. ${ }^{25}$ gasified feedlot manure with steam in a bench scale fluidized bed reactor using a mixture of 25 wt \% limestone and 75 wt \% silica sand as the bed material. These authors reported that limestone addition in the silica bed could prevent agglomeration.

This study present the results obtained from experiments of poultry litter gasification using a bubbling fluidized bed gasifier. The main objectives of this study are to investigate (a) the influence of equivalence ratio (ER, i.e., fed to stoichiometric air ratio) (b) steam to biomass ratio (SBR, i.e., steam to poultry litter mass ratio), (c) reactor temperature $\left(T_{\mathrm{g}}\right)$, and $(\mathrm{d})$ the effect of limestone (blended with the poultry litter), on the performance of the gasification process.

\section{EXPERIMENTAL DETAILS}

2.1. Materials. Poultry litter was collected from a local poultry farm in The Netherlands. Since poultry litter is a heterogeneous fuel with a bulk density of $360 \mathrm{~kg} / \mathrm{m}^{3}$, it was carefully prepared (collected, partially dried, sieved, etc.) with a particle size in the range of $0.7-2.8$ $\mathrm{mm}$ before gasifying. The moisture and ash content in the feedstock were 22.1 as received and $17.6 \%$ dry basis, respectively. Ultimate and proximate analyses as well as heating value of the poultry litter are reported in Table 1. The composition of poultry litter can be

Table 1. Chemical Characteristic of Poultry Litter

\begin{tabular}{lc}
\multicolumn{1}{c}{ component } & poultry litter $(\% \mathrm{w} / \mathrm{w})$ \\
moisture content (a.r.) & 22.10 \\
ash content (d.b.) & $17.55 \pm 0.06$ \\
volatile matter (d.b.) $^{a}$ (d.b.) & $73.65 \pm 0.02$ \\
fixed carbon $^{a}$ (d.b. & $8.81 \pm 0.02$ \\
$\mathrm{C}$ (d.a.f.) & $54.70 \pm 0.37$ \\
$\mathrm{H}$ (d.a.f.) & $6.43 \pm 0.07$ \\
$\mathrm{~N}$ (d.a.f.) & $6.48 \pm 0.01$ \\
$\mathrm{Cl}$ (d.a.f.) & $0.70 \pm 0.02$ \\
$\mathrm{~S}$ (d.a.f.) & $0.90 \pm 0.03$ \\
$\mathrm{O}^{a}$ (d.a.f.) & $30.79 \pm 0.25$ \\
$\mathrm{LHV}$ (MJ/kg) (a.r.) & $13.53 \pm 0.41$ \\
cellulose (d.b.) & 12.88 \\
hemicellulose (d.b.) & 11.72 \\
lignin (d.b.) & 14.16 \\
extractives & (d.b.) \\
\hline
\end{tabular}

${ }^{a}$ Calculated by difference, a.r. - as received, d.b. - dry basis, d.a.f. dry and ash free basis. ${ }^{b}$ Containing water and ethanol extractives.

represented by the empirical formula $\mathrm{CH}_{1.40} \mathrm{O}_{0.42} \mathrm{~N}_{0.10}$ (dry and ash free basis). Fixed carbon content was calculated by subtracting the moisture, ash, and volatile matter content from $100 \%$. The elemental composition (C, H, N, S) was determined by a Vario EL cube elemental analyzer. Oxygen content in the poultry litter was calculated by the difference, whereas higher heating value was measured using an Isoperibol Calorimeter 6200 (Parr Instruments). Chlorine content in the poultry litter, cyclone fines, and bottom ash was determined according to CEN/TS 15408:2006. Poultry litter ash (generated at $550{ }^{\circ} \mathrm{C}$ according to BS EN 14775:2009 standard) was digested and analyzed by inductively coupled plasma (ICP), and the results for the individual metals are reported as their corresponding oxides in Table 2. The elemental analysis of poultry litter ash shows that it has high amounts of silica, sodium, potassium, phosphorus, and aluminum oxides.

2.2. Experimental Facility and Test Procedure. The experiments were carried out within the BRISK EU FP7 framework project using an air-blown bubbling fluidized bed gasifier at the Energy Research Centre of The Netherlands (ECN). The experimental setup consists of biomass hopper with two feeding screws, air preheater, bubbling fluidized bed gasification reactor, cyclone, hot and cold particulate filters and afterburner/flare for combustion of the product gas, as shown in Figure 1. The biomass hopper was equipped with a 
Table 2. Chemical Composition of the Poultry Litter Ash As Received Basis (Ash at $550{ }^{\circ} \mathrm{C}$ )

$\begin{array}{lrlc}\text { oxides } & \text { concentration (wt \%) } & \text { oxides } & \text { concentration }\left(10^{-3} \text { wt \%) }\right. \\ \mathrm{SiO}_{2} & 35.67 & \mathrm{TiO}_{2} & 32 \\ \mathrm{P}_{2} \mathrm{O}_{5} & 17.51 & \mathrm{BaO} & 17 \\ \mathrm{CaO} & 12.29 & \mathrm{NiO} & 12 \\ \mathrm{SO}_{3} & 11.90 & \mathrm{Cr}_{2} \mathrm{O}_{3} & 3.7 \\ \mathrm{MgO} & 9.23 & \mathrm{MoO}_{3} & 2.7 \\ \mathrm{Na}_{2} \mathrm{O} & 5.27 & \mathrm{~V}_{2} \mathrm{O}_{5} & 2.1 \\ \mathrm{~K}_{2} \mathrm{O} & 3.32 & \mathrm{SeO}_{3} & 1.5 \\ \mathrm{Al}_{2} \mathrm{O}_{3} & 2.40 & \mathrm{HgO} & 1.0 \\ \mathrm{Fe}_{2} \mathrm{O}_{3} & 1.51 & \mathrm{PbO}_{2} & 0.57 \\ \mathrm{ZnO} & 0.37 & \mathrm{As} \mathrm{O}_{3} & 0.50 \\ \mathrm{MnO} & 0.34 & \mathrm{CoO} & 0.29 \\ \mathrm{CuO} & 0.10 & \mathrm{CdO} & 0.13 \\ & & \mathrm{BeO} & 0.11\end{array}$

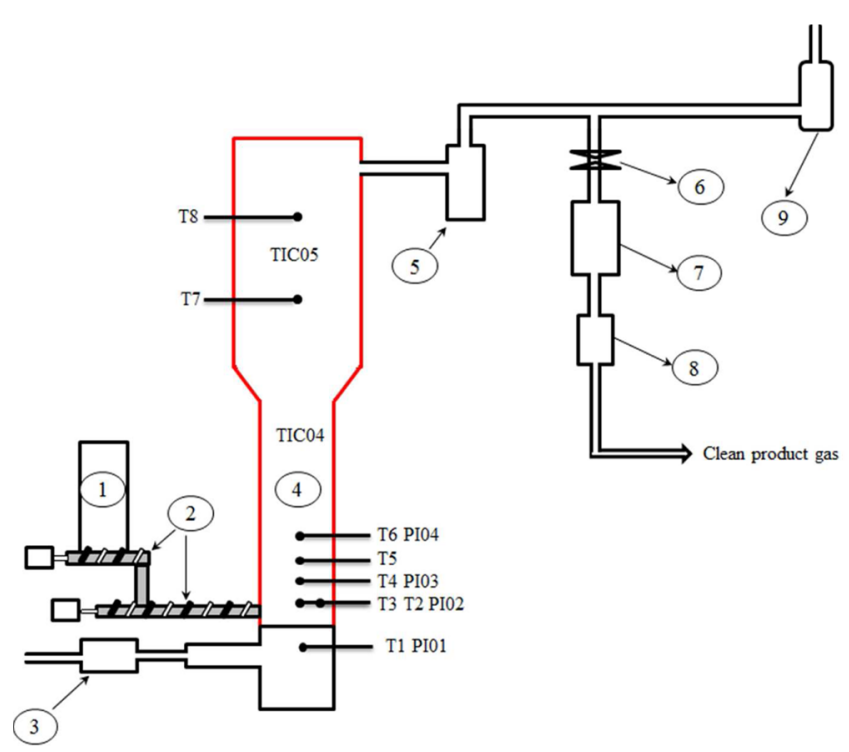

Figure 1. Schematic diagram of WOB gasifier (1) biomass hopper; (2) feeding screws; (3) air preheater; (4) gasifier reactor; (5) cyclone; (6) valve; (7) hot filter; (8) cold filter; (9) flare.

stirrer which was used to prevent settling and bridging of the feedstock and to ensure the fuel supply was consistent. The gasification reactor consists of a bed section $(500 \mathrm{~mm}$ high and $74 \mathrm{~mm}$ internal diameter (ID) and a freeboard section (600 $\mathrm{mm}$ high and an ID of $108 \mathrm{~mm}$ ). External heat was supplied to maintain the temperature within the reactor. Poultry litter was fed through a mechanical screw feeder under $\mathrm{N}_{2}\left(1 \mathrm{dm}^{3} / \mathrm{min}\right)$ to prevent backflow of the product gases. The feeding point was $50 \mathrm{~mm}$ above the bottom plate. The fluidizing media were heated to $160{ }^{\circ} \mathrm{C}$ before being introduced from the bottom of the reactor (Table 3). The experiments were carried out at various air, $\mathrm{N}_{2}$, and steam mixtures at different temperatures. The cyclone at the outlet stream was used to separate the solid particles (elutriated char and ashes) from the product gas. After each experiment, cyclone fines were collected and weighed, and the char elutriation rate was calculated over the period of gasification test. The amount of downstream dust that escaped from the cyclone was not collected and measured in this study. The downstream sections of the gasifier up to cold filter were well insulated, heated, and maintained at $400{ }^{\circ} \mathrm{C}$ to avoid tar condensation. Tar and moisture samples were taken through a sampling port located after the cyclone and hot filtration unit in the downstream section. The product gases were combusted in a flare.

Silica sand with a particle size in the range $0.25-0.50 \mathrm{~mm}$ (mean particle size of $0.31 \mathrm{~mm}$ ) and bulk and absolute densities of 1422 and $2620 \mathrm{~kg} / \mathrm{m}^{3}$ respectively was used as the bed material. To avoid any influence of accumulated ash from previous experiments, $1.2 \mathrm{~kg}$ of fresh silica sand was used for each test. The minimum theoretical fluidizing velocity was around $0.097 \mathrm{~m} / \mathrm{s}$ at $20{ }^{\circ} \mathrm{C}$, calculated using Wen and Yu's correlation. ${ }^{26}$

Gasification tests were conducted in such a way that the gas velocity (based on total flow rate fed and the average temperature of the gasifier) of the fluidizing medium (air and $\mathrm{N}_{2}$ ) was constant throughout the tests. The feed rate of poultry litter was varied to achieve the required ER in the tests (Table 3). Air, $\mathrm{N}_{2}$, and steam were injected from the bottom of the gasifier. The ER was varied from 0.18 to 0.41 by adjusting the air and $\mathrm{N}_{2}$ flow rate. The experimental campaigns were performed using either a mixture of poultry litter $(92 \%)$ and limestone $(8 \%)$ or solely poultry litter. The limestone was supplied by Rheinkalk GmbH (Brilon, Germany) with particle size in the range $0.9-1.2 \mathrm{~mm}$. The feed rate of the fuel was between 0.49 and $0.66 \mathrm{~kg} / \mathrm{h}$. Four experiments were performed each working day, and the feeding rate was reported on an averaged basis over the period of gasification time. The bed temperature of the reactor remained constant during each test. The flow rate of air, $\mathrm{N}_{2}$, and steam was adjusted to ensure that the bed was properly fluidized. At higher ER, the $\mathrm{N}_{2}$ flow rate was decreased while increasing the air flow rate to keep constant the fluidization velocity. Therefore, decrease in $\mathrm{N}_{2}$ concentration was evident in product gas with an increase in ER. Three gasification tests were carried out to investigate the effect of steam injection on the product gas composition and its heating value. Experiments were performed at different temperatures $\left(700 \leq T_{\mathrm{g}} \leq\right.$ $\left.800{ }^{\circ} \mathrm{C}\right)$, equivalence ratios $(0.18 \leq \mathrm{ER} \leq 0.41)$, and steam to biomass mass ratios $(0.26 \leq \mathrm{SBR} \leq 0.33)$.

2.3. Measurement Methods. The composition (CO, $\mathrm{CO}_{2}, \mathrm{C}_{2} \mathrm{H}_{2}$, $\mathrm{CH}_{4}, \mathrm{C}_{2} \mathrm{H}_{4}, \mathrm{C}_{2} \mathrm{H}_{6}, \mathrm{C}_{6} \mathrm{H}_{6}, \mathrm{C}_{7} \mathrm{H}_{8}, \mathrm{~N}_{2}, \mathrm{COS}, \mathrm{H}_{2} \mathrm{~S}$, and $\mathrm{Ne}$ ) of the filtered dry product gases were analyzed an online micro gas chromatograph (GC) (Varian, CP-4900). The micro GC was calibrated with a gas mixture containing a specified neon concentration. Precautions were taken to make sure the $\mathrm{H}_{2}$ and Ne peaks were well separated. An ABB gas analyzer was used to determine the $\mathrm{H}_{2}$ and $\mathrm{O}_{2}$ content in the product gas. The online gas analyzer measures permanent gases as well as sulfur containing compounds $\left(\mathrm{H}_{2} \mathrm{~S}\right.$ and $\left.\mathrm{COS}\right)$. $\mathrm{Ne}$ gas $(10 \mathrm{~mL} / \mathrm{min})$ was introduced into the gasifier continuously to measure the product gas flow rate, which was calculated according to eq 1 using the concentration of $\mathrm{Ne}$ in the product gas.

$$
\gamma_{i}=\left(\frac{\beta}{\mathrm{Ne}}\right)
$$

where, $\gamma_{i}$ represents the flow rate of dry product gas $\left(\mathrm{m}^{3} / \mathrm{min}\right), \beta$ is the $\mathrm{Ne}$ flow rate $(\mathrm{mL} / \mathrm{min})$ and $\mathrm{Ne}$ the concentration of $\mathrm{Ne}(\mathrm{ppm})$ in the product gas. Char elutriation rate was calculated by dividing the mass of char collected in the cyclone by the time of the experiment. Permanent gas measurements were carried out as per the method described by van Paasen et al. ${ }^{27}$ The $\mathrm{N}_{2}$ fed into the gasifier was corrected for the gas yields and gas compositions. Gas composition measurements were performed continuously at $4 \mathrm{~min}$ intervals for around $30 \mathrm{~min}$, and four samples of tar were taken at the same instants.

A short description of solid-phase adsorption (SPA) cartridge preparation, extraction, tar sampling methodology, and chromatographic analysis is provided here. SPA cartridges were assembled by packing $500 \mathrm{mg}$ of aminopropyl silica sorbent. A stainless steel needle with the plastic cap was attached to one side, and a conical rubber stopper closed the other side of the SPA cartridge. The extraction procedure and chromatographic analysis described by Osipovs ${ }^{28}$ has been modified for the purpose of this work. Tar compounds were extracted from the sorbent by addition of $3 \times 600 \mu \mathrm{L}$ of dichloromethane. tert-Butylcyclohexane and 4-ethoxy phenol were added as internal standards to the tar solutions. Calibration curves using naphtalene/tert-butylcyclohexane and phenol/4-ethoxy phenol were applied to integrate the aromatic and phenolic tars, respectively.

A Thermo Scientific Trace 1310 GC with flame ionization detector (GC-FID) was used to analyze the tars. Helium flow, column, injection volume, injection port, and oven settings were kept the same 
Table 3. Summary of Experimental Tests

\begin{tabular}{|c|c|c|c|c|c|c|c|c|c|c|c|c|c|c|}
\hline \multirow[b]{3}{*}{ test number } & \multicolumn{14}{|c|}{ feedstock type } \\
\hline & \multicolumn{4}{|c|}{ poultry litter } & \multicolumn{4}{|c|}{ poultry litter with limestone } & \multicolumn{4}{|c|}{ poultry litter limestone } & \multicolumn{2}{|c|}{$\begin{array}{c}\text { poultry litter } \\
\text { with limestone }\end{array}$} \\
\hline & 1 & 2 & 3 & 4 & 5 & 6 & 7 & 8 & 9 & 10 & 11 & 12 & 13 & 14 \\
\hline $\begin{array}{l}\text { poultry litter feed rate, } \\
\mathrm{kg} / \mathrm{h} \text { (a.r.) }\end{array}$ & \multicolumn{4}{|c|}{0.66} & \multicolumn{4}{|c|}{0.49} & \multicolumn{4}{|c|}{0.61} & \multicolumn{2}{|c|}{0.57} \\
\hline limestone $(\mathrm{kg} / \mathrm{h})$ & \multicolumn{4}{|c|}{0.0} & \multicolumn{4}{|c|}{0.04} & \multicolumn{4}{|c|}{0.05} & \multicolumn{2}{|c|}{0.05} \\
\hline throughput $\left(\mathrm{kg} / \mathrm{h}-\mathrm{m}^{2}\right)$ & \multicolumn{4}{|c|}{155} & \multicolumn{4}{|c|}{113} & \multicolumn{4}{|c|}{141} & \multicolumn{2}{|c|}{132} \\
\hline temperature of gasifier, & \multicolumn{4}{|c|}{700} & \multicolumn{4}{|c|}{700} & \multicolumn{4}{|c|}{750} & \multicolumn{2}{|c|}{800} \\
\hline $\begin{array}{l}\text { temperature of gasifying } \\
\text { medium, }{ }^{\circ} \mathrm{C}\end{array}$ & \multicolumn{4}{|c|}{160} & \multicolumn{4}{|c|}{160} & \multicolumn{4}{|c|}{160} & \multicolumn{2}{|c|}{160} \\
\hline $\begin{array}{l}\text { steam to biomass ratio, } \\
\text { SBR (-) }\end{array}$ & 0 & 0 & 0 & 0.24 & 0 & 0 & 0 & 0.33 & 0 & 0 & 0 & 0.26 & 0 & 0 \\
\hline equivalence ratio, ER (-) & 0.18 & 0.22 & 0.30 & 0.30 & 0.29 & 0.35 & 0.41 & 0.35 & 0.23 & 0.28 & 0.33 & 0.28 & 0.25 & 0.30 \\
\hline air flow rate, $\left(\mathrm{dm}^{3} / \mathrm{min}\right)$ & 6 & 7.2 & 10 & 10 & 7 & 8.5 & 10 & 8.5 & 7 & 8.5 & 10 & 8.5 & 7 & 8.5 \\
\hline $\begin{array}{l}\text { nitrogen flow rate, }\left(\mathrm{dm}^{3} /\right. \\
\text { min) }\end{array}$ & 6 & 4.8 & 2 & 1 & 5 & 3.5 & 2 & 2 & 5 & 3.5 & 2 & 2 & 5 & 3.5 \\
\hline steam flow rate, $\mathrm{kg} / \mathrm{h}$ & 0 & 0 & 0 & 0.125 & 0 & 0 & 0 & 0.125 & 0 & 0 & 0 & 0.125 & 0 & 0 \\
\hline $\begin{array}{l}\text { fluidising medium flow } \\
\text { rate, } \mathrm{dm}^{3} / \mathrm{min}\end{array}$ & 12 & 12 & 12 & 13.6 & 12 & 12 & 12 & 13.1 & 12 & 12 & 12 & 13.1 & 12 & 12 \\
\hline $\begin{array}{l}\text { fluidization velocity, } \mathrm{m} / \mathrm{s} \\
\left(20^{\circ} \mathrm{C}\right)\end{array}$ & 0.098 & 0.097 & 0.094 & 0.095 & 0.097 & 0.096 & 0.094 & 0.095 & 0.097 & 0.096 & 0.094 & 0.095 & 0.097 & 0.096 \\
\hline $\begin{array}{l}\text { superficial gas velocity } \\
\text { based on the total } \\
\text { product gas yield, } \mathrm{m} / \mathrm{s} \\
\left(T_{\mathrm{g}}\right)\end{array}$ & 0.21 & 0.24 & 0.24 & 0.24 & 0.22 & 0.21 & 0.20 & 0.19 & 0.24 & 0.23 & 0.23 & 0.22 & 0.25 & 0.24 \\
\hline
\end{tabular}

as for GC mass selective detector (GC-MSD) analysis. The FID temperature was maintained at $240{ }^{\circ} \mathrm{C}$. Air, hydrogen, and carrier gas $\left(\mathrm{N}_{2}\right)$ flow were adjusted to 350,35 , and $40 \mathrm{~mL} / \mathrm{min}$, respectively.

Tar yields are expressed on a mass basis as $\mathrm{g}_{\text {tar }} / \mathrm{kg}_{\text {daf-poultry litter }}$ in order to eliminate any dilution effect of the product gas when the biomass feed rate is reduced ${ }^{29}$ or when the oxygen to nitrogen ratio is reduced to adjust for lower $\mathrm{ER}^{30} \mathrm{Tar}$ in this paper refers to GC detectable tar including those tar compounds eluted from phenol $(M$ $\approx 94 \mathrm{~g} / \mathrm{mol})$ to benz $[\mathrm{a}]$ anthracene $(M \approx 228 \mathrm{~g} / \mathrm{mol})$. Because of the poor measurement reliability of the lighter tars (e.g., benzene, toluene), the SPA results are not included in the present work, but instead the micro-GC results are used for the discussion.

Moisture, ammonia $\left(\mathrm{NH}_{3}\right)$ and hydrochloric acid $(\mathrm{HCl})$ content was measured once a day at each temperature. An impinger bottle containing $100 \mathrm{~mL}$ of $0.1 \mathrm{M} \mathrm{HNO}_{3}$ was placed in bath at $4{ }^{\circ} \mathrm{C}$ after the hot filter for the sampling of moisture, $\mathrm{NH}_{3}$, and $\mathrm{HCl}$. The moisture content was determined by the mass difference of the impinger bottle before and after the sampling. The principle of $\mathrm{NH}_{3}$ measurement was based on membrane diffusion and its content was measured using an electro-conductivity detector. $\mathrm{HCl}$ content was determined by the means of ion chromatography (conductivity detection) using a Dionex IonPac AS18 analytical column.

Table 3 presents a summary of the experiments. The experimental tasks focused on the analysis of the product gas composition, ammonia emissions, and tar concentration at different temperatures, ER, and SBR to identify the optimum operating conditions for feedstock's which have high ash content.

2.4. Performance Analysis. The efficiency of a gasifier is normally expressed in terms of the cold gas efficiency (CGE). CGE is defined as the ratio of the chemical energy of the produced gas to the chemical energy of the feedstock. It is imperative to mention that while calculating the CGE, both the heating value of the gas produced and feedstock have to be in the same units, i.e., either LHV or higher heating value (HHV). In this study the LHV of the biomass and product gas is used in calculating CGE. Carbon conversion efficiency (CCE) and hydrogen conversion efficiency (HCE) were calculated by dividing the carbon and hydrogen in the dry product gas by the amount of carbon and hydrogen fed into the gasifier. To assess the gasification process performance CGE, CCE, and HCE are determined according to following equations. ${ }^{12}$

$$
\begin{aligned}
& \operatorname{CGE}\left(\eta_{\mathrm{cg}}\right)=\left(\frac{\mathrm{LHV}_{\mathrm{g}} \times \dot{m}_{\mathrm{g}}}{\mathrm{LHV}_{\mathrm{f}} \times \dot{m}_{\mathrm{f}}}\right) \times 100 \\
& \operatorname{CCE}\left(\eta_{\mathrm{cc}}\right)=\left(\frac{\mathrm{C}_{\mathrm{o}, \text { drygas }}}{C_{\mathrm{i}, \text { daf }}}\right) \times 100 \\
& \operatorname{HCE}\left(\eta_{\mathrm{hc}}\right)=\left(\frac{H_{\mathrm{o} \text {,drygas }}}{H_{\mathrm{i}, \text { daf }}}\right) \times 100
\end{aligned}
$$

where $\dot{m}_{\mathrm{f}}$ is the feed rate of solid fuel, $\dot{m}_{\mathrm{g}}$ is product gas flow rate in $\mathrm{kg} / \mathrm{h}$, and $\mathrm{LHV}_{\mathrm{g}}$ and $\mathrm{LHV}_{\mathrm{f}}$ are calorific values of produced gas and solid fuel, respectively. For $C_{\mathrm{i}}, C_{\mathrm{o}}, H_{\mathrm{i}}$, and $H_{\mathrm{o}}$ the subscript i represents the feeding rate of carbon and hydrogen on a daf basis, and o is the flow rate of carbon and hydrogen in the product gas. The superficial velocity of the product gas (at the reactor temperature) presented in Table 3 is calculated according to the formula given by Siedlecki et al. $^{31}$

\section{RESULTS AND DISCUSSION}

Figure 2 shows the concentration of the major gas components and temperature profiles in the bed and freeboard over the run time of a typical experiment. The temperature and gas composition profiles had effectively stabilized after $10 \mathrm{~min}$. However, to ensure steady state had been reached, an additional $40 \mathrm{~min}$ were allowed before sampling the product gas for tars and other gas measurement.

Table 4 presents the main results of the experimental campaign. It should be noted that the gas compositions presented in Table 4 are on an as-measured basis, whereas gas compositions and yields reported in figures are presented on a $\mathrm{N}_{2}$ free basis. At higher ER, the $\mathrm{N}_{2}$ flow rate was reduced while increasing the air flow rate to keep initial fluidization velocity of 


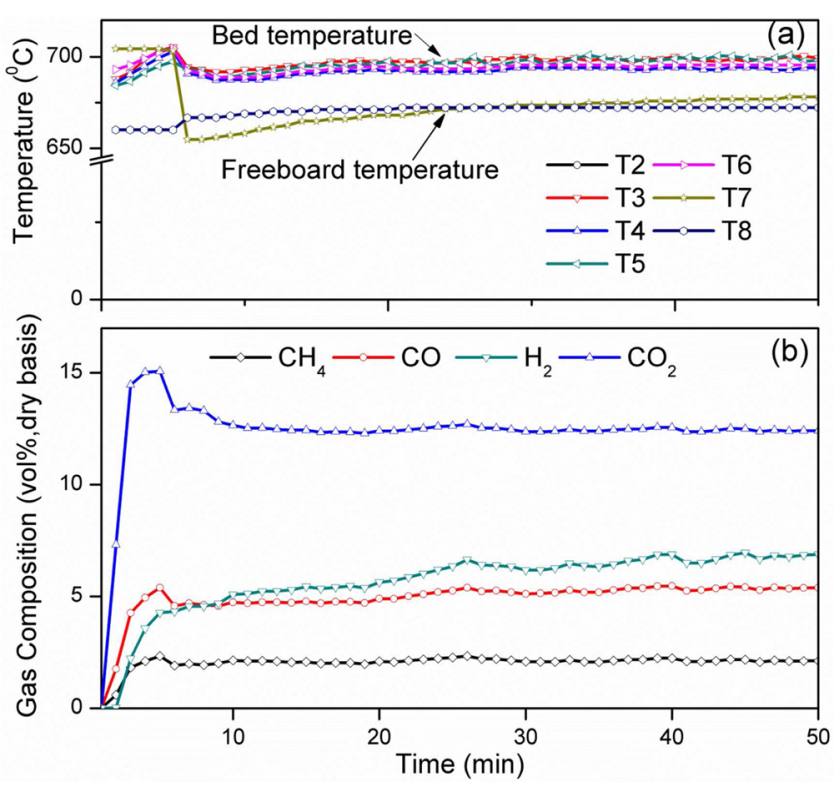

Figure 2. Bed and freeboard temperature and gas composition evolution in a poultry litter test at $700{ }^{\circ} \mathrm{C}$ and $\mathrm{ER}=0.18$ : (a) temperature profile (b) product gas composition. the bed the same. Consequently, a decrease in $\mathrm{N}_{2}$ concentration was evident in the product gas with an increase in ER. The mean values of the concentration of individual product gas compounds and the total tar measured were reported. The corresponding standard deviations (SD) were calculated to be less than 3\%; therefore, other calculations such as LHV, CGE, CCE, HCE, and gas yield were performed on an averaged basis of product gas compositions. SD of the gas yields are reported in the figures.

3.1. Effect of Limestone Addition. This section describes the product gas composition and performance of the poultry litter gasification process without and with limestone addition at $700{ }^{\circ} \mathrm{C}$ and an ER 0.30 (experiment numbers 3 and 5). Limestone was one of the first additives used in gasifiers to improve the gasification in terms of tar reduction. ${ }^{32}$ However, since the effect of limestone addition on biomass gasification with air at atmospheric pressure is not well documented, an attempt was made to understand how limestone might affect the gasification performance for the poultry litter used in this study. The total tar content decreased by $12 \%$ without having much influence on product gas yield (Table 4). A similar conclusion has been drawn by Gómez-Barea et al. ${ }^{33}$ while gasifying orujillo and meat and bone meal waste in an air-blown bubbling fluidized bed at atmospheric pressure using lime as a bed material (or blend with ofite).

\section{Table 4. Experimental Test Results}

\begin{tabular}{|c|c|c|c|c|c|c|c|c|c|c|c|c|c|c|}
\hline test number & 1 & 2 & 3 & 4 & 5 & 6 & 7 & 8 & 9 & 10 & 11 & 12 & 13 & 14 \\
\hline \multicolumn{15}{|c|}{ Gas Composition from the Steady State Conditions (\%v/v, dry as measured) } \\
\hline $\mathrm{H}_{2}$ & 7.34 & 11.60 & 12.04 & 17.58 & 5.78 & 5.16 & 2.44 & 6.62 & 10.29 & 9.48 & 9.00 & 14.98 & 10.49 & 8.95 \\
\hline $\mathrm{Ar}$ & 0.41 & 0.42 & 0.55 & 0.53 & 0.47 & 0.57 & 0.79 & 0.78 & 0.42 & 0.53 & 0.61 & 0.53 & 0.40 & 0.51 \\
\hline $\mathrm{N}_{2}$ & 69.00 & 58.53 & 53.88 & 46.5 & 69.39 & 68.13 & 69.87 & 64.22 & 60.66 & 60.36 & 58.83 & 52.10 & 60.27 & 62.35 \\
\hline $\mathrm{CH}_{4}$ & 1.86 & 2.55 & 2.46 & 2.59 & 1.83 & 1.62 & 1.43 & 1.73 & 2.71 & 2.37 & 2.30 & 2.37 & 2.54 & 2.30 \\
\hline $\mathrm{CO}$ & 5.41 & 8.52 & 9.69 & 9.35 & 5.06 & 5.01 & 4.23 & 4.38 & 8.40 & 8.32 & 8.08 & 7.57 & 9.14 & 7.50 \\
\hline $\mathrm{CO}_{2}$ & 11.36 & 13.22 & 15.60 & 17.74 & 12.29 & 13.74 & 15.03 & 16.08 & 12.69 & 13.68 & 15.25 & 16.92 & 12.78 & 14.15 \\
\hline $\mathrm{C}_{2} \mathrm{H}_{4}$ & 0.89 & 1.14 & 1.11 & 1.10 & 0.91 & 0.82 & 0.81 & 0.86 & 1.42 & 1.30 & 1.26 & 1.26 & 1.40 & 1.27 \\
\hline $\mathrm{C}_{2} \mathrm{H}_{6}$ & 0.19 & 0.29 & 0.29 & 0.32 & 0.18 & 0.17 & 0.14 & 0.18 & 0.18 & 0.18 & 0.18 & 0.19 & 0.10 & 0.10 \\
\hline $\mathrm{C}_{2} \mathrm{H}_{2}$ & 0.017 & 0.019 & 0.016 & 0.013 & 0.018 & 0.017 & 0.019 & 0.017 & 0.025 & 0.028 & 0.020 & 0.017 & 0.023 & 0.015 \\
\hline $\mathrm{H}_{2} \mathrm{~S}$ & 0.046 & 0.062 & 0.057 & 0.091 & 0.042 & 0.051 & 0.026 & 0.070 & 0.023 & 0.030 & 0.028 & 0.042 & 0.019 & 0.023 \\
\hline $\cos$ & 0.003 & 0.004 & 0.003 & 0.002 & 0.002 & 0.002 & 0.002 & 0.001 & 0.001 & 0.001 & 0.001 & 0.001 & 0.001 & 0.001 \\
\hline $\mathrm{C}_{6} \mathrm{H}_{6}$ & 0.092 & 0.115 & 0.112 & 0.112 & 0.097 & 0.083 & 0.078 & 0.086 & 0.155 & 0.133 & 0.13 & 0.121 & 0.166 & 0.156 \\
\hline $\mathrm{C}_{7} \mathrm{H}_{8}$ & 0.041 & 0.054 & 0.055 & 0.055 & 0.040 & 0.038 & 0.034 & 0.038 & 0.048 & 0.046 & 0.050 & 0.047 & 0.033 & 0.037 \\
\hline \multicolumn{15}{|c|}{ Other Results } \\
\hline $\begin{array}{l}\mathrm{NH}_{3}(\mathrm{ppmv} \text { in dry } \\
\text { gas) }\end{array}$ & & & 39552 & & & 29540 & & & & 27031 & & & & \\
\hline $\begin{array}{l}\text { moisture in the } \\
\text { product gas (\%vol) }\end{array}$ & & & 19.6 & & & 19.5 & & & & 16.7 & & & & \\
\hline $\begin{array}{l}\mathrm{HCl}\left(\mathrm{mg} / \mathrm{Nm}^{3} \text {, dry }\right. \\
\text { gas) }\end{array}$ & & & 20.9 & & & 88.5 & & & & 14.7 & & & & \\
\hline $\begin{array}{l}\text { total GC detectable } \\
\operatorname{tar}\left(\mathrm{g} / \mathrm{kg}_{\mathrm{daf}} \text { poultry }\right. \\
\text { litter })\end{array}$ & 4.40 & 6.25 & 7.22 & 8.59 & 6.36 & 5.85 & 3.72 & 3.97 & 6.42 & 5.19 & 3.89 & 2.89 & 5.66 & 3.25 \\
\hline $\begin{array}{l}\text { gas yield }\left(\mathrm{Nm}^{3} / \mathrm{kg}_{\text {daf }}\right. \\
\text { poultry litter } \mathrm{N}_{2} \\
\text { free })\end{array}$ & 0.75 & 1.09 & 1.15 & 1.36 & 1.12 & 1.14 & 1.03 & 1.13 & 1.15 & 1.10 & 1.12 & 1.25 & 1.39 & 1.24 \\
\hline $\begin{array}{l}\mathrm{LHV}\left(\mathrm{MJ} / \mathrm{Nm}^{3} \text {, dry }\right. \\
\text { gas) }\end{array}$ & 3.11 & 4.53 & 4.72 & 5.36 & 2.91 & 2.69 & 2.17 & 2.87 & 4.55 & 4.24 & 4.12 & 4.74 & 4.52 & 3.95 \\
\hline $\begin{array}{l}\mathrm{C} \text { entrainment in the } \\
\text { cyclone }\left(\mathrm{g} / \mathrm{kg}_{\mathrm{daf}}\right. \\
\text { poultry litter })\end{array}$ & 53.17 & 78.51 & 98.27 & 104.22 & 58.51 & 77.25 & 47.28 & 63.26 & 72.11 & 76.47 & 70.51 & 70.51 & 33.43 & 33.43 \\
\hline $\begin{array}{l}\text { carbon conversion } \\
\text { efficiency }(\%)\end{array}$ & 49.1 & 72.5 & 81.8 & 88.0 & 70.8 & 73.1 & 70.0 & 71.8 & 78.2 & 76.4 & 79.0 & 80.2 & 89.2 & 81.0 \\
\hline cold gas efficiency (\%) & 42.3 & 69.7 & 72.5 & 83.6 & 55.2 & 43.0 & 33.0 & 48.4 & 75.6 & 68.0 & 65.2 & 73.5 & 84.6 & 69.3 \\
\hline $\begin{array}{l}\text { hydrogen conversion } \\
\text { efficiency }(\%)\end{array}$ & 27.3 & 40.2 & 41.0 & 39.8 & 32.3 & 29.2 & 20.7 & 24.1 & 41.1 & 37.6 & 36.3 & 36.7 & 42.9 & 37.8 \\
\hline
\end{tabular}



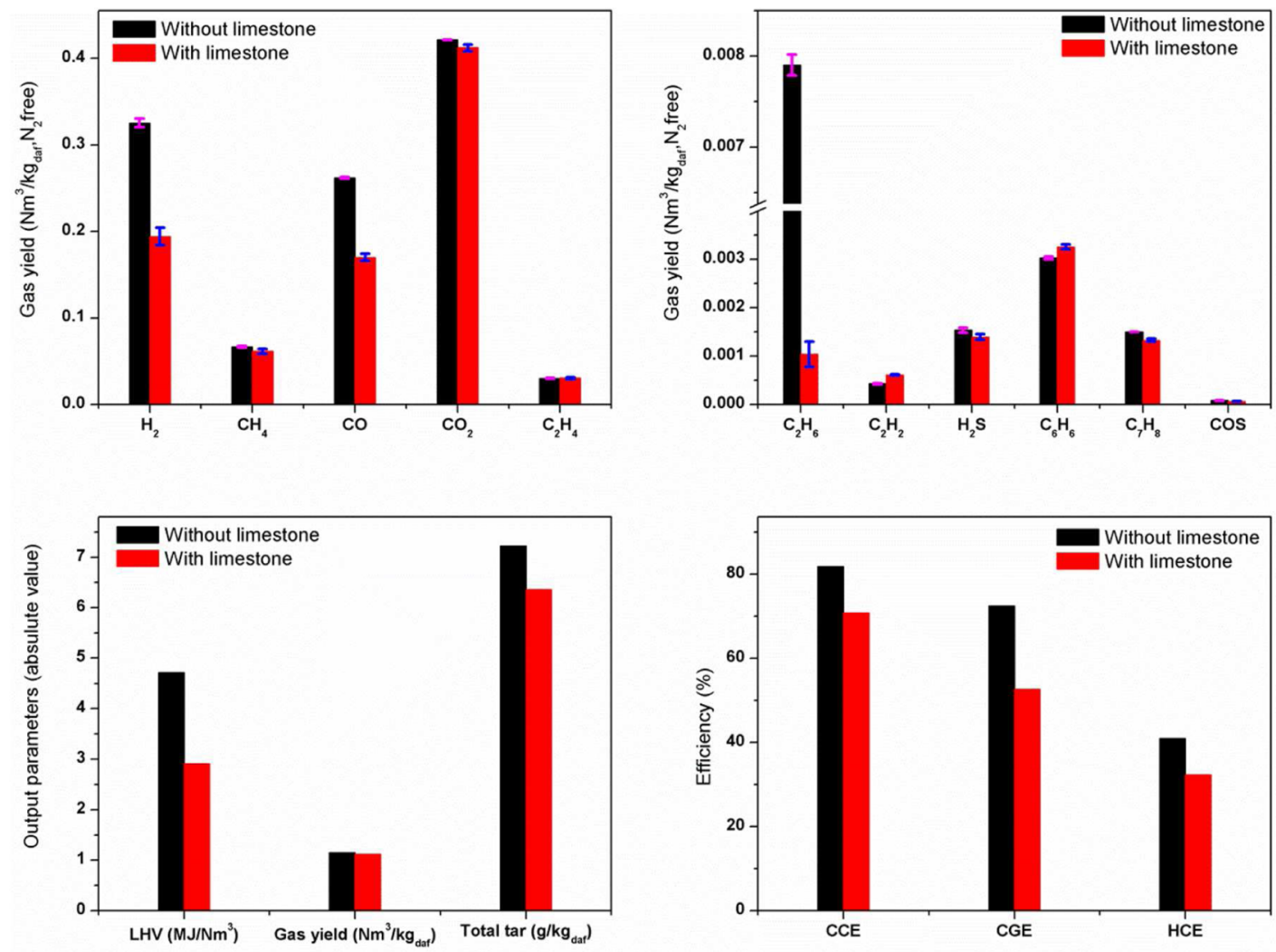

Figure 3. Effect of limestone on the composition of the product gas and gasifier performance (gas yields are on a $\mathrm{N}_{2}$ free basis).

Limestone addition proportionally reduced the poultry litter feed rate ( $8 \%$ by weight) and also changed gas composition significantly with a consequent effect on it is heating value (calculated on the basis of gas composition without the contribution of tar content) and CGE. From Figure 3, it can be seen that limestone addition has a significant influence on product gas composition. The concentration of the major product gas components fell except for $\mathrm{C}_{2} \mathrm{H}_{2}$ and $\mathrm{C}_{6} \mathrm{H}_{6}$ when poultry litter was blended with limestone. Moreover, reported errors are well within the acceptable range $(\sim 3 \%)$. The total gas yield remained stable (between 1.12 to $1.15 \mathrm{Nm}^{3} / \mathrm{kg}_{\mathrm{daf}}$ ), while the LHV dropped from 4.72 to $2.91 \mathrm{MJ} / \mathrm{Nm}^{3}$. As a consequence, a significant decrease in CGE is observed from $72.5 \%$ to $55.2 \%$. Limestone addition does not have as significant an effect on CCE as it does on the CGE and LHV, which indicates that its addition might have reduced the char elutriation rate in the cyclone. The measurements presented in Table 4 confirmed this by inspection of the calculated elutriation rate of carbon/char. About 10.69\% (58.51 $\mathrm{g} / \mathrm{kg}_{\text {daf }}$ ) of total carbon fed into the gasifier was collected from the cyclone fines in the case of blended poultry litter and limestone, whereas without limestone blending the percentage of carbon recovered in cyclone fines is $17.96 \%\left(98.27 \mathrm{~g} / \mathrm{kg}_{\mathrm{daf}}\right)$.

In general, the bed material acts as a reservoir of generated ash and its elements (especially the less volatile elements such as $\mathrm{Si}, \mathrm{Al}, \mathrm{Ca}, \mathrm{Mg}$, and $\mathrm{P}$ ). The collected elutriated char and ash fines form the cyclones were analyzed, and the results revealed that, without limestone, about $58 \%$ of total $\mathrm{Cl}$ and $44 \%$ of total $\mathrm{S}$ end up in the cyclone fines, whereas the corresponding values when limestone was added to the feed were 3 and $53 \%$ respectively at a temperature of $700{ }^{\circ} \mathrm{C}$ and an $\mathrm{ER} \approx 0.30$ (experiment numbers 3 and 5). As shown in Table 4, the concentration of $\mathrm{H}_{2} \mathrm{~S}$ and $\mathrm{COS}$ in the product gas decreases with limestone addition suggesting that it might have favored the $\mathrm{S}$ and $\mathrm{Cl}$ recoveries in the bed and/or cyclone fines; similar results have been reported elsewhere. ${ }^{34,35}$ However, in contrast to the findings of other researchers, $\mathrm{HCl}$ content in the gas phase increases with limestone addition at $700{ }^{\circ} \mathrm{C}$ and an ER of 0.35 . Nevertheless, at elevated temperature $\left(750^{\circ} \mathrm{C}\right.$ and an ER of 0.28$)$ the results are in line with findings reported. ${ }^{34,35}$ The fate of $\mathrm{N}, \mathrm{S}$, and $\mathrm{Cl}$ bound with the feedstock is presented in the section 3.5 (Table 6).

While gasifiying poultry litter without any limestone addition, the bed agglomeration could be seen at a gasifier temperature of $750{ }^{\circ} \mathrm{C}$. Therefore, as a countermeasure to avoid defluidization and agglomeration issues at higher temperature in a fluidized bed gasfier with feedstock's of higher ash content, limestone addition has become a necessity. Further discussion will focus on comparing the influence of different process parameters on poultry litter gasification blended with limestone.

3.2. Effect of Temperature on Gasification Performance. The effect of reactor temperature on the gasification performance of poultry litter blended with limestone was investigated over different temperatures $\left(700 \leq T_{\mathrm{g}} \leq 800{ }^{\circ} \mathrm{C}\right)$ and an ER of $\sim 0.30$ (experiments number 5, 10, and 14). The variables analyzed include gas composition, product gas yield $\left(\mathrm{N}_{2}\right.$ free basis), heating value, tar yield, CCE, CGE, and HCE, and the results are shown in Figures 4 and 5. It is evident from Figure 4 that the gasifier temperature has a significant influence on the product gas composition since higher temperature favors endothermic reactions, i.e., char gasification, water gas shift reaction, and cracking of higher hydrocarbons and tars. ${ }^{36}$ The increase in $\mathrm{CO}$ and $\mathrm{H}_{2}$ production is due to the improved Boudouard reaction and water gas reactions, as well as tar 

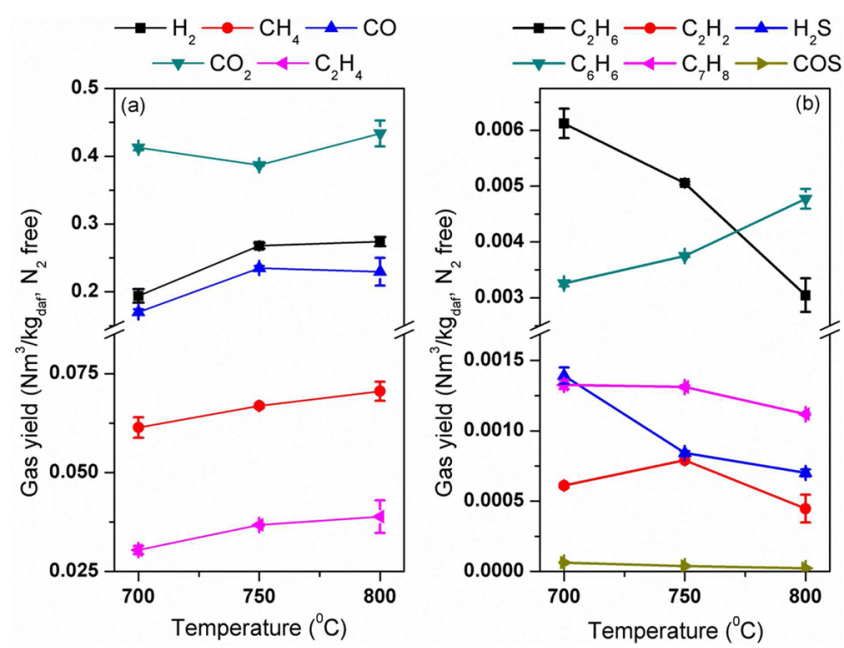

Figure 4. Effect of temperature on the composition of the product gas at $E R \approx 0.30$ (a) yield of major gas species (b) yield of light hydrocarbon gas species in the product gas.

cracking and reforming reactions. The concentrations of $\mathrm{CH}_{4}$, $\mathrm{C}_{2} \mathrm{H}_{4}$, and benzene show a similar trend and increases with temperature. On the other hand, gasification temperature has almost no effect on the yields of $\mathrm{C}_{2} \mathrm{H}_{2}, \mathrm{C}_{7} \mathrm{H}_{8}$ over the tested range of temperature, while the production of $\mathrm{C}_{2} \mathrm{H}_{6}$ and $\mathrm{H}_{2} \mathrm{~S}$ decreased with temperature. The elevated temperature favors thermal cracking and steam reforming reactions, explaining the observed decrease in $\mathrm{C}_{2} \mathrm{H}_{6}$ concentration in this study. A similar conclusion was drawn by Turn et al. $^{37}$ in the temperature range $750-800{ }^{\circ} \mathrm{C}$.

Sulfur concentration in the product gas depends on the sulfur content in the fuel and the gasifier temperature. Mass balance analysis in section 3.5 shows that approximately $45-70 \%$ of the sulfur is bound to the cyclone fines. The sulfur in the gas phase is present in the form of $\mathrm{H}_{2} \mathrm{~S}$ and $\mathrm{COS}$ which accounts for about $8 \%$ of total sulfur fed into the gasifier at $800{ }^{\circ} \mathrm{C}$ and an ER of 0.25 . The concentration of $\mathrm{H}_{2} \mathrm{~S}$ decreases with an increase in the gasification temperature, whereas the concentration of COS remains fairly constant throughout the temperatures studied (Figure 4). It is considered that the balancer of the sulfur remains in the bed.
Normally, the $\mathrm{HCl}$ concentration in the gas phase increases with temperature due to chlorinated tar cracking at higher temperature. ${ }^{27}$ However, it is observed from Table 4 that the concentration of $\mathrm{HCl}$ in the gas phase decreased with increasing gasifier temperature from 700 to $750{ }^{\circ} \mathrm{C}$. Since poultry litter ash has higher concentration of $\mathrm{K}, \mathrm{P}$, and $\mathrm{Ca}$ (due to the addition of limestone), the probability of forming potassium chloride $(\mathrm{KCl})$, phosphorus chloride $\left(\mathrm{PCl}_{3}\right)$, and calcium chloride $\left(\mathrm{CaCl}_{2}\right)$ compounds are highly likely, and consequently most of the $\mathrm{Cl}$ is bounded in the bottom ash and/ or cyclone fines. Normally, $\mathrm{KCl}$ condenses on cold surfaces, whereas fines are collected from the hot cyclones therefore part of the $\mathrm{Cl}$ cannot be measured. The amount of $\mathrm{Cl}$ recovered from the cyclone fines increases from 2.94 to $25 \%$ with an increase in temperature from 700 to $750{ }^{\circ} \mathrm{C}$. Detailed analysis of mass closure is presented in Section 3.5 (Table 5) which will provide a better insight into the fate of the $\mathrm{S}, \mathrm{Cl}$, and $\mathrm{N}$ bound to the feedstock's for experiments number 3, 6, and 10 .

The high concentration of $\mathrm{NH}_{3}$ in the product gas indicates that $\mathrm{NH}_{3}$ is the main nitrogenous compound formed during the gasification of poultry litter (Table 4). $\mathrm{NH}_{3}$ concentration further correlated to the nitrogen content in the feedstock. The measured $\mathrm{NH}_{3}$ decreased with an increase in the temperature of gasifcation which is in-line with investigations performed on a lab-scale bubbling fluidized bed gasifier by Zhou et al. ${ }^{38}$ Furthermore, it confirms the theory proposed by Zhou et al. ${ }^{38}$ that at higher temperature the conversion of $\mathrm{NH}_{3}$ to $\mathrm{N}_{2}\left(3 \mathrm{H}_{2}+\right.$ $\mathrm{N}_{2} \leftrightarrow 2 \mathrm{NH}_{3}$ ) is the dominant thermochemical process which consequently decides the fate of fuel bound nitrogen in a fluidized bed gasifier. It is worth mentioning that the amounts of chlorine and sulfur in the product gas are well below the required maximum allowable concentration limit of the fuel to be used in a boiler or gas engine. ${ }^{27}$

Figure 5 clearly shows that a higher temperature increases the product gas yield (from 1.12 to $1.24 \mathrm{Nm}^{3} / \mathrm{kg}_{\text {daf }}$ ) and LHV (from 2.91 to $4.24 \mathrm{MJ} / \mathrm{Nm}^{3}$ ) while decreasing total tar content (from 7.22 to $6.26 \mathrm{~g} / \mathrm{kg}_{\text {daf }}$ ). This is attributed to the fact that increasing the temperature improves char and tar cracking (into light hydrocarbon gases and secondary tar species). However, at a higher temperature in the gasifier, $\mathrm{CO}$ oxidation and the water gas shift reaction dominate, which increases the yield of $\mathrm{CO}_{2}$ and consequently lowered the LHV of the product gas. The influence of temperature on the gasifier's performance is reported in Figure 5b. It is apparent that an increase in
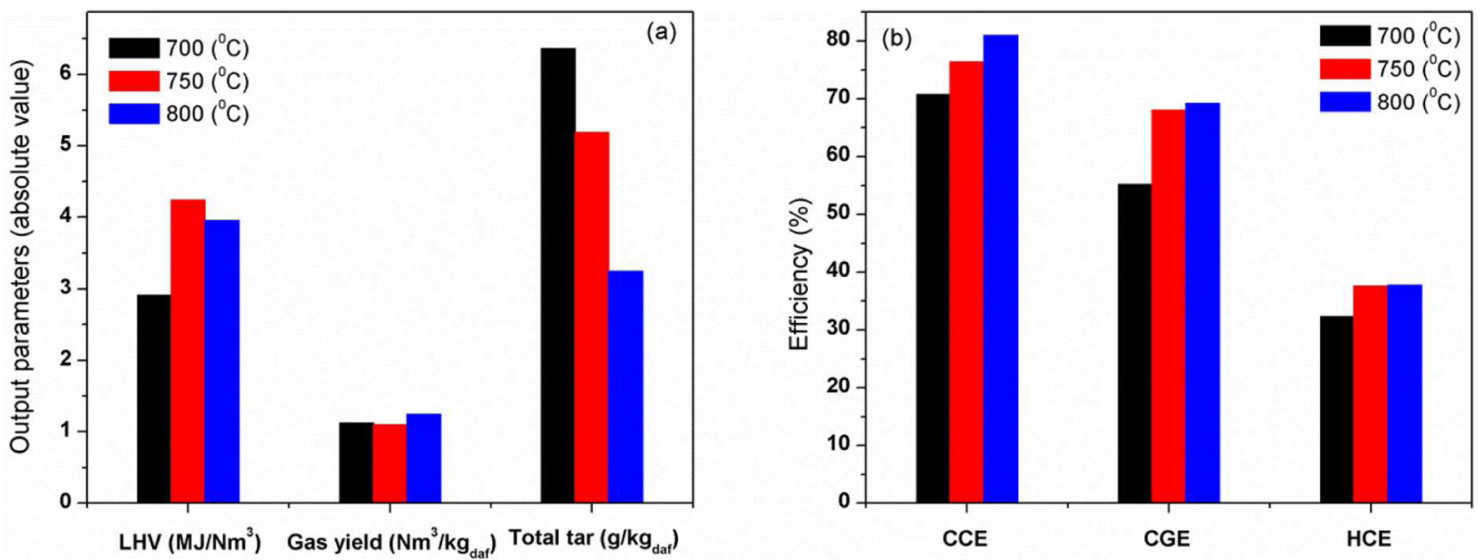

Figure 5. Effect of temperature on (a) LHV, product gas $\left(\mathrm{N}_{2}\right.$ free) and total tar yields (b) the performance of gasification at ER $\approx 0.30$ (experiments number 5, 10, and 14). 

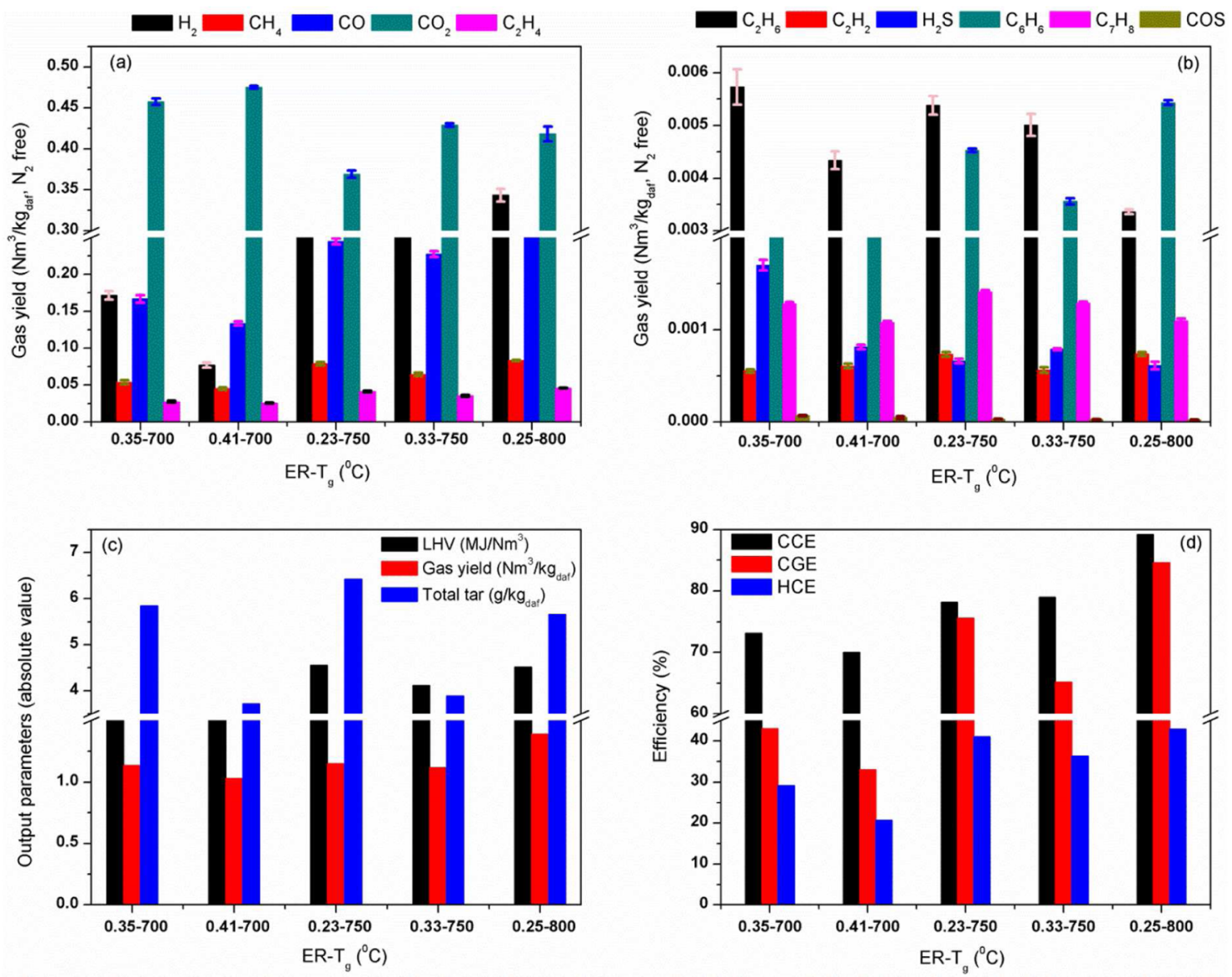

Figure 6. $(\mathrm{a}-\mathrm{d})$ Effects of ER on the composition of product gas and gasifier performance (gas yields are on an $\mathrm{N}_{2}$ free basis).

temperature improved the CCE over the range of temperatures investigated. Similarly, an increase in temperature has a significant effect on CGE which increased from $55.2 \%$ at 700 ${ }^{\circ} \mathrm{C}$ to more than $69.3 \%$ at $800{ }^{\circ} \mathrm{C}$ under the same operating conditions $(\mathrm{ER} \approx 0.30)$. The main reason for a carbon conversion in the range of $80 \%$ could be unconverted carbon from cyclone, which accounted for $6-14 \%$ of the total carbon fed into the gasifier. The hydrogen conversion into the dry product gas is relatively low compared to the carbon conversion; the reason could be due to loss of hydrogen in moisture and tar compounds. In the temperature range from 700 to $750{ }^{\circ} \mathrm{C}, \mathrm{HCE}$ was observed to increase by $5 \%$. However, a higher gasification temperature does not show any significant effect on hydrogen conversion. The moisture content in the product gas was measured on a daily basis, which decreased with gasification temperature (Table 4).

3.3. Effect of ER on Poultry Litter Gasification. The profiles of the product gas composition, gas yield, LHV, CGE, $\mathrm{CCE}, \mathrm{HCE}$, and tar yield from poultry litter gasification under different combinations of ER and temperature are presented in Figure 6. An increase in ER results in a reduction of $\mathrm{H}_{2}$ and $\mathrm{CO}$ contents in the product gas due to an increased amount of $\mathrm{O}_{2}$ available in the reactor for reaction with the volatiles and char combustion which results in increase of $\mathrm{CO}_{2}$ production and degrades the quality of product gas.

It is important to note that the ER does not have much influence on $\mathrm{CH}_{4}$. Regarding light hydrocarbons, Figure $6 \mathrm{~b}$ shows that the concentration of ethane, benzene, and toluene fell slightly with ER. At the same time, acetylene and $\mathrm{H}_{2} \mathrm{~S}$ do not show any consistent trend over the range of temperatures and ER studied. At lower temperatures, acetylene concentration was fairly constant but showed declining behavior with ER at elevated temperatures.

Since the product gas yield is reported on an $\mathrm{N}_{2}$ and dry and ash free basis, the ER does not have a noticeable effect on product gas yields as evident from the Figure 6c. Moreover, LHV decreases slightly due to dilution of the product gas with nitrogen and diminishing combustible gas contents (calculation of LHV was done on an as measured basis). In contrast to the product gas yield, the ER does impact total tar yield, and a significant drop from 6.36 to $2.93 \mathrm{~g} / \mathrm{kg}_{\mathrm{daf}}$ is observed at $750{ }^{\circ} \mathrm{C}$ due to the oxidation reaction of aromatics. ${ }^{39}$ Moreover, an increase in ER does not benefit in terms of the chemical energy of the product gas except for the tar reduction during the gasification process.

The maximum product gas yield, LHV, CCE and CGE is achieved at an ER of 0.25 when the gasifier was operating at $800{ }^{\circ} \mathrm{C}$. This process condition (refer to Figure 6) yielded a product gas with a chemical composition (on dry basis) of $\mathrm{H}_{2}$ : 10.78\%, CO: $9.38 \%, \mathrm{CH}_{4}: 2.61$, and $\mathrm{CO}_{2}: 13.13$, and LHV of $4.52 \mathrm{MJ} / \mathrm{Nm}^{3}$. The carbon entrainment at this operating condition was the lowest (5.2\% of the total carbon fed into the gasifier) among all other conditions and resulted in the highest CGE of $89.2 \%$.

In line with the findings of several other reports in the scientific literature, it is found that increasing the ER above 0.25 produces a low quality product gas due to dilution with $\mathrm{N}_{2}$ and other noncombustible gas components. CGE decreased with 

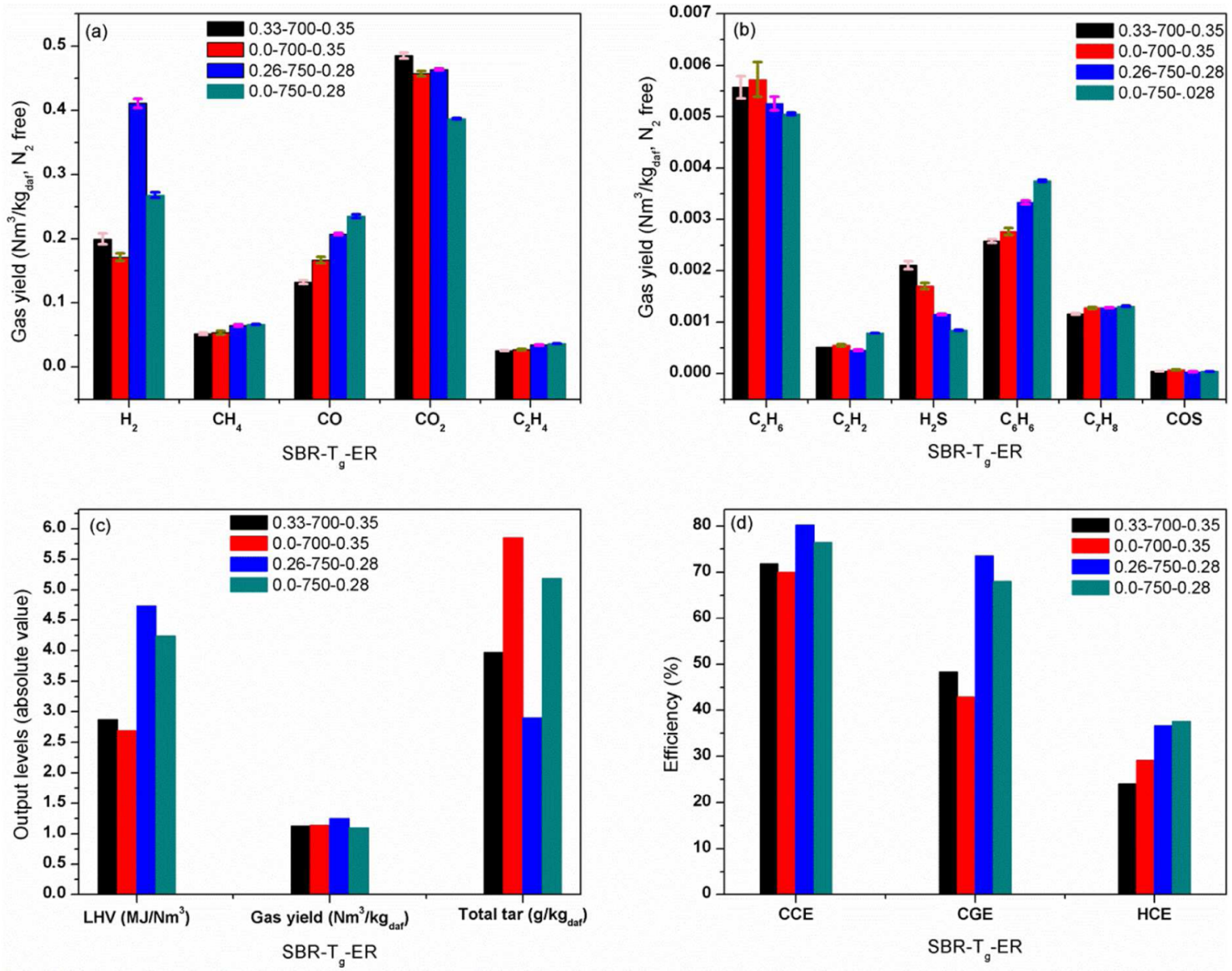

Figure 7. $(a-d)$ Effects of SBR on the composition of product gas and gasifier performance.

ER due to the lower chemical energy of the product gas. The reason is that at higher ERs, more air is fed to the gasifier promoting the char/carbon combustion reactions (producing more $\mathrm{CO}_{2}$ and $\mathrm{H}_{2} \mathrm{O}$, lowering the heating value of the product gas) but resulting in higher carbon conversion efficiency. HCE on the other hand decreased with ER, and this could be due to the dominant combustion reactions (char combustion and oxidation of $\mathrm{H}_{2}$ ) promoting the moisture yield in the product gas. As outlined in Gomez-Barea et al. ${ }^{40}$ selection of the optimum condition of ER and tar evolution can be achieved once the product gas application is defined. For example, the gasifier has to be operated below an ER of 0.25 when the aim is having higher heating value of the product gas. On the other hand, if product gas is to be used in combustion engines where low tar content is mandatory, the gasifier has to be operated at high ER, which will reduce the tar content.

In conclusion, it is not recommended to have too low or too high ER in biomass/waste gasification processes. However, the optimum operating condition of ER totally depends on other process conditions and potential application of the product gas. Narvaez et al. ${ }^{41}$ proposed an optimum operating range of ER of $0.18<\mathrm{ER}<0.45$ in the gasifier. The research findings of this study proposed a narrow and more accurate condition of the ER of 0.25 to optimize the performance of poultry litter gasification.

3.4. Effect of Steam Injection. The influence of SBR on the product gas yield is investigated at 700 and $750{ }^{\circ} \mathrm{C}$. Steam gasification experiments are performed to optimize the hydrogen production while increasing the CCE. It can be seen that steam injection improves the gas yield and LHV of dry gas, while it decreases the tar yield. The steam injection increases the product gas yield because steam injection favors tar steam reforming and the water gas shift reaction. Figure 7 shows that steam injection has a significant influence on hydrogen production. The addition of steam resulted in an increase of $53 \%$ in hydrogen production $\left(0.26 \mathrm{Nm}^{3} / \mathrm{kg}_{\text {daf }} \mathrm{v} / \mathrm{s}\right.$ $\left.0.41 \mathrm{Nm}^{3} / \mathrm{kg}_{\text {daf }}\right)$ when compared with no steam injection at ER of 0.28 and temperature of $750{ }^{\circ} \mathrm{C}$. It is found that $\mathrm{H}_{2}$ and $\mathrm{CO}_{2}$ concentration increases with steam injection, while $\mathrm{CH}_{4}$ and $\mathrm{CO}$ decreased. Similar conclusions have been drawn by varying the SBR. ${ }^{42}$ It confirms that the water gas shift reaction plays a dominant role to improve the hydrogen production. In contrast, it does not have much influence on the other hydrocarbon concentrations. At $700{ }^{\circ} \mathrm{C}$ with SBR of 0.33 and $750{ }^{\circ} \mathrm{C}$ with SBR of 0.26 , the total tar content decreased during the process, from 5.85 to 3.97 and 5.19 to $2.89 \mathrm{~g} / \mathrm{kg}_{\text {daf }}$ poultry litter, respectively. A significant drop in total tar concentration is observed in Figure $7 \mathrm{c}$, which confirms that steam tar reforming reactions are enhanced with the steam injection in the gasifier even at a relatively low temperature level, most probably due to the catalyzed action of lime in the bed.

Figure 7 shows that, in spite of raising the $\mathrm{H}_{2}$ yield in the gas, SBR does not influence the LHV as much compared to other parameters analyzed, probably because the increase in $\mathrm{H}_{2}$ is outweighed by the decrease in $\mathrm{CO}$ and $\mathrm{CH}_{4}$. However, steam injection improves the chemical energy content of the product gas, resulting in an increase in CGE and CCE of around 5\%. It can be seen in Figure $7 \mathrm{~d}$ that HCE is significantly lower at 700 ${ }^{\circ} \mathrm{C}$ when steam is added (as compared to the case without steam), indicating that the use of steam at low temperature is 
Table 5. Mass Balance of Gasification Tests

\begin{tabular}{|c|c|c|c|c|c|c|c|c|c|}
\hline \multirow[b]{2}{*}{ elements } & \multicolumn{3}{|c|}{$\begin{array}{l}\text { poultry litter without limestone at } 700{ }^{\circ} \mathrm{C} \text { and } \\
\qquad \mathrm{ER}=0.30\end{array}$} & \multicolumn{3}{|c|}{$\begin{array}{l}\text { poultry litter with limestone at } 700{ }^{\circ} \mathrm{C} \text { and } \\
\qquad \mathrm{ER}=0.35\end{array}$} & \multicolumn{3}{|c|}{$\begin{array}{l}\text { poultry litter with limestone at } 750{ }^{\circ} \mathrm{C} \text { and } \\
\text { ER }=0.28\end{array}$} \\
\hline & input & output & relative error $(\%)^{a}$ & input & output & relative error (\%) & input & output & relative error (\%) \\
\hline $\mathrm{C}(\mathrm{kg} / \mathrm{h})$ & 0.234 & 0.224 & -4.16 & 0.170 & 0.147 & -13.62 & 0.214 & 0.182 & -14.97 \\
\hline $\mathrm{H}(\mathrm{kg} / \mathrm{h})$ & 0.044 & 0.043 & -3.04 & 0.033 & 0.031 & -4.68 & 0.041 & 0.039 & -5.23 \\
\hline $\mathrm{O}(\mathrm{kg} / \mathrm{h})$ & 0.433 & 0.436 & 0.81 & 0.344 & 0.372 & 7.94 & 0.395 & 0.390 & -1.28 \\
\hline $\mathrm{N}(\mathrm{kg} / \mathrm{h})$ & 0.734 & 0.680 & -7.34 & 0.749 & 0.848 & 12.94 & 0.754 & 0.744 & -1.34 \\
\hline $\mathrm{S}(\mathrm{kg} / \mathrm{h})$ & 0.004 & 0.003 & -15.30 & 0.0028 & 0.0032 & 14.36 & 0.003 & 0.004 & 22.83 \\
\hline $\mathrm{Cl}(\mathrm{kg} / \mathrm{h})$ & 0.002 & 0.001 & -37.03 & 0.0017 & 0.0002 & -90.23 & 0.002 & 0.001 & -74.30 \\
\hline $\operatorname{ash}(\mathrm{kg} / \mathrm{h})$ & 0.091 & 0.089 & -2.76 & 0.072 & 0.078 & 8.68 & 0.090 & 0.102 & 13.07 \\
\hline
\end{tabular}

Table 6. Fate of Nitrogen, Sulfur and Chlorine from the Feedstock

\begin{tabular}{|c|c|c|c|c|c|c|c|c|c|c|}
\hline & \multirow{2}{*}{$\frac{\text { total input from poultry litter }(100 \%)}{\text { input }(\%)}$} & \multicolumn{3}{|c|}{$\begin{array}{l}\text { poultry litter without limestone at } \\
700{ }^{\circ} \mathrm{C} \text { and } \mathrm{ER}=0.30 \text { (Exp. } \\
\text { No. 3) }\end{array}$} & \multicolumn{3}{|c|}{$\begin{array}{c}\text { poultry litter with limestone at } \\
700{ }^{\circ} \mathrm{C} \text { and ER }=0.35 \text { (Exp. } \\
\text { No. 6) }\end{array}$} & \multicolumn{3}{|c|}{$\begin{array}{l}\text { poultry litter with limestone at } \\
750{ }^{\circ} \mathrm{C} \text { and } \mathrm{ER}=0.28 \text { (Exp. } \\
\text { No. 10) }\end{array}$} \\
\hline & & \multicolumn{3}{|c|}{ output (\%) } & \multicolumn{3}{|c|}{ output (\%) } & \multicolumn{3}{|c|}{ output (\%) } \\
\hline elements & & gas & cyclone & bed & gas & cyclone & bed & gas & cyclone & bed \\
\hline $\mathrm{Cl}$ & 100 & 0.87 & 57.66 & 4.44 & 5.05 & 4.71 & $\mathrm{NM}^{b}$ & 0.67 & 25.10 & $\mathrm{NM}$ \\
\hline S & 100 & 21.56 & 44.42 & 18.71 & 26.55 & 77.84 & 10.01 & 12.22 & 71.26 & 39.30 \\
\hline $\mathrm{N}^{a}$ & 100 & 101.12 & 0.34 & 0.10 & 94.94 & 7.45 & 0.05 & 75.70 & 7.50 & 0.25 \\
\hline
\end{tabular}

not consumed and so it leads to a decrease in HCE. Although it is evident that steam injection improves the hydrogen production, it decreases the yield of higher hydrocarbons such as $\mathrm{C}_{2} \mathrm{H}_{6}, \mathrm{C}_{6} \mathrm{H}_{6}$, and $\mathrm{C}_{7} \mathrm{H}_{8}$. Considering the energy required to product steam, it might not be economically feasible to operate at high SBR. Most importantly, if the gasification process is conducted in authothermal mode, as it will most probably be in small to medium plants, steam injection at constant ER reduced the temperature, and therefore, it could lead to a reduction of gas quality and higher tar yield, lowering the process efficiency. It may be concluded that SBR has significant effects on hydrogen production, reforming the tars, CCE, and CGE. It can be recommended that steam injection is desirable for the production of hydrogen rich product gas.

3.5. Mass Balance Analysis and fate of $\mathrm{N}, \mathrm{S}$, and $\mathrm{Cl}$ of the Feed (Poultry Litter). The mass balance calculations for the main elemental species are presented in Table 5. The input stream comprises feed, air, steam, and moisture content in the feed, whereas the outlet stream consists of dry gas, unconverted char collected from the bed and cyclone fines, $\mathrm{NH}_{3}, \mathrm{HCl}$, and moisture present in the gas. The elemental compositions of input and output streams are taken into account for calculating the mass closure while applying the law of conservation of mass. Dry air fed to the gasifier consists of oxygen and nitrogen only, with a mass ratio of 23.2-76.8. The following assumptions are made for calculating the mass balance (i) elutriation of bed material is negligible, (ii) $\sum_{i=1}^{n} M_{i}=\sum_{j=1}^{n} M_{\mathrm{o}}$ where, $i$ and $j$ represent the input and output constituents of each elemental, (iii) added limestone is bound with the bottom ash, (iv) accumulation rate of ash and char in the bed is averaged over the day.

Table 5 shows that the relative errors are in the range of $\pm 15 \%$ (except for $\mathrm{Cl}$ ), which are within an acceptable limit. The amount of $\mathrm{Cl}$ present in the bottom ash was not measured, explaining the poor mass balance closure obtained for $\mathrm{Cl}$. Table 5 indicates that $\mathrm{Cl}$ mass closure without limestone has a lower relative error compared to when limestone is added. The presence of high amounts of mineral elements such as $\mathrm{K}, \mathrm{P}, \mathrm{Na}$ in poultry litter, and $\mathrm{Ca}$ from the limestone might have led to a high retention of $\mathrm{S}$ and $\mathrm{Cl}$ in the ash in the bed and elutriated cyclone fines which is in agreement with previous finding. ${ }^{43}$

An attempt was made to explain the fate of N, S, and Cl from the poultry litter based on measurements. Table 6 illustrates the detailed analysis of the measurements. It can be seen from Table 6 that without limestone, major fraction of $\mathrm{Cl}$ is measured in cyclone fines $(57.6 \%)$, whereas 4.5 and $0.57 \%$ are in the bed ash and gas phase, respectively. Moreover, about $37 \%$ is still missing; the reason could be that $\mathrm{Cl}$ was also present in the form of $\mathrm{KCl}$ which condenses on the cold surfaces. The percentage $\mathrm{Cl}$ increased from 0.87 to $5.05 \%$ in the vapor phase with limestone addition, but a significant change in $\mathrm{Cl}$ percentage is observed in the cyclone fines at $\mathrm{ER}=0.35$ and $700{ }^{\circ} \mathrm{C}$. A similar trend is observed in the case of $S$ content in the gas phase at lower temperature. It is interesting to see that most of the nitrogen associated with feedstock is converted into ammonia $\left(\mathrm{NH}_{3}\right)$. Furthermore, the research findings revealed that $\mathrm{NH}_{3}$ formation decreased with an increase in gasifier temperature in agreement with the literature. ${ }^{38}$ In conclusion, limestone addition has shown a positive influence on the reduction of $\mathrm{S}$ and $\mathrm{Cl}$ content in the gas phase when the gasifier was running at a relatively high temperature $\left(>750{ }^{\circ} \mathrm{C}\right)$. Table 6 indicates that $\mathrm{Cl}$ is mostly bound to bottom ash, whereas a large portion of $S$ is collected from the cyclone fines when poultry litter was blended with limestone.

\section{CONCLUSION}

Despite having high ash content, poultry litter blended with limestone was successfully gasified in a bubbling fluidized bed without agglomeration problems. Therefore, limestone addition ( $0.08 \mathrm{~kg}$ limestone $/ \mathrm{kg}$ poultry litter in the present work) is recommended for the smooth running of a gasifier with reasonable efficiency when poultry litter is gasified. Total tar and $\mathrm{Cl}$ content in the gas phase were relatively low compared 
to other biomass and wastes. In contrast, higher $\mathrm{N}_{2}$ content in the feed resulted in a high concentration of $\mathrm{NH}_{3}$ in the gas. The effects of several process parameters on product gas production were experimentally investigated. This study revealed that gasifier temperature is the most important parameter with respect to gas production and heating value of the gas. The product gas had an average heating value of $4.5 \mathrm{MJ} / \mathrm{Nm}^{3}$, which can be used, properly cleaned, in gas engines or boilers. Steam injection in the gasification process slightly increased the product gas yield at $750{ }^{\circ} \mathrm{C}$ resulting in a CGE of $73.5 \%$ and generated the lowest tar concentration of $2.89 \mathrm{~g} / \mathrm{kg}_{\text {daf }}$. Although the effect of ER and SBR was relatively small compared to temperature, it did influence hydrogen production. Relatively high $\mathrm{C}$ loss was observed due to high gas velocity, which needs to be optimized. In addition, to assess the suitability of using the bottom ash and cyclone fines as a soil amender, leaching test need to be performed.

In summary, taking into account poultry litter as a low quality fuel, the research findings from this study demonstrate its potential as an alternative source of energy available at the farm level for the gasification purposes. It is important to mention that the present experimental work was made in allothermal mode (heat was provided to the gasifier by an external oven and so the ER and SBR was varied at constant temperature). In small to medium scale plants such as those to be found likely in farms, the gasification process will be conducted most probably in autothermal mode, and the present results, despite being useful, have to be scaled up with caution. In a follow-up paper, the present experimental data will be used to validate a model and to scale-up the results to autothermal industrial units applicable to farms.

\section{AUTHOR INFORMATION}

\section{Corresponding Author}

*(M.K.) E-mail: marzena.kwapinska@ul.ie.

Notes

The authors declare no competing financial interest.

\section{ACKNOWLEDGMENTS}

The financial support for this project provided by the EU project Biomass Research Infrastructure for Sharing Knowledge (BRISK) is gratefully acknowledged. The authors wish to thank the Energy Research Centre of Netherlands (ECN) for the technical support and cooperation. D.S.P. acknowledges funding from the People Programme (Marie Curie Actions) of the European Union's Seventh Framework Programme FP7/ 2007-2013/under REA Grant Agreement No. [289887] and postgraduate research scholarship received from the University of Limerick, Ireland. M.K. acknowledges the financial support provided by Enterprise Ireland Competence Centre for Biorefining \& Bioenergy (CC/2009/1305A) and INTERREG IVB NEW REsource Innovation Network for European Waste Project number 317J-RENEW. A.G.-B. acknowledges the help of University of Seville for his stay in Limerick. A.H. is supported by the Earth and Natural Sciences Doctoral Studies Programme which is funded by the Higher Education Authority (HEA) through the Programme for Research at Third Level Institutions, Cycle 5 (PRTLI-5) and is cofunded by the European Regional Development Fund (ERDF).

\section{ABBREVIATIONS}

$\mathrm{ER}=$ equivalence ratio
SBR = steam to biomass ratio

$\mathrm{LHV}=$ lower heating value

$\mathrm{CCE}=$ carbon conversion efficiency

$\mathrm{CGE}=$ cold gas efficiency

$\mathrm{HCE}=$ hydrogen conversion efficiency

$\mathrm{GC}=$ gas chromatography

SPA $=$ solid phase adsorption

ICP = inductively coupled plasma

$\mathrm{SD}=$ standard deviation

FID = flame ionization detector

MSD $=$ mass selective detector

\section{REFERENCES}

(1) MacLeod, M.; Gerber, P.; Mottet, A.; Tempio, G.; Falcucci, A.; Opio, C.; Vellinga, T.; Henderson, B.; Steinfeld, H. Food and Agriculture Organization of the United Nations (FAO): Rome, 2013.

(2) Foged, H. L.; Flotats Ripoll, X.; Blasi, A. B.; Palatsi, J. C.; Magrí, A. A.; Schelde, K. M. The European Commission, Directorate-General Environment, 2011, 138 pp.

(3) Gerber, P.; Opio, C.; Steinfeld, H. Animal Production and Health Division; Food and Agriculture Organization of the United Nations: Viale delle Terme di Caracalla, 2007, 153.

(4) Hoornweg, D.; Bhada-Tata, P. The World Bank: Washington, DC, 2012

(5) Rand, T.; Haukohl, J.; Marxen, U. The World Bank: Washington, DC, 1999.

(6) Bujak, J. W. Renewable Energy 2015, 83, 1174-1186.

(7) Lynch, D.; Henihan, A. M.; Bowen, B.; Lynch, D.; McDonnell, K.; Kwapinski, W.; Leahy, J. Biomass Bioenergy 2013, 49, 197-204.

(8) Cantrell, K.; Ro, K.; Mahajan, D.; Anjom, M.; Hunt, P. G. Ind. Eng. Chem. Res. 2007, 46, 8918-8927.

(9) Kelleher, B.; Leahy, J.; Henihan, A.; O'dwyer, T.; Sutton, D.; Leahy, M. Bioresour. Technol. 2002, 83, 27-36.

(10) Billen, P.; Costa, J.; Van der Aa, L.; Van Caneghem, J.; Vandecasteele, C. J. Cleaner Prod. 2015, 96, 467-475.

(11) Arena, U. Waste Manage. 2012, 32, 625-639.

(12) Basu, P. Biomass Gasification and Pyrolysis: Practical Design and Theory; Academic Press: New York, 2010.

(13) Priyadarsan, S.; Annamalai, K.; Sweeten, J.; Mukhtar, S.; Holtzapple, M.; et al. Trans. ASAE 2004, 47, 1689-1696.

(14) Thanapal, S. S.; Annamalai, K.; Sweeten, J. M.; Gordillo, G. Appl. Energy 2012, 97, 525-531.

(15) Joseph, P.; Tretsiakova-McNally, S.; McKenna, S. Waste Manage. 2012, 32, 701-709.

(16) Hamilton, J. E.; Adams, J. M.; Northrop, W. F. Energy Fuels 2014, 28, 3255-3261.

(17) Taupe, N.; Lynch, D.; Wnetrzak, R.; Kwapinska, M.; Kwapinski, W.; Leahy, J. Waste Manage. 2016, DOI: 10.1016/j.wasman.2016.02.036.

(18) Raman, K. P.; Walawender, W. P.; Fan, L. Ind. Eng. Chem. Process Des. Dev. 1980, 19, 623-629.

(19) Di Gregorio, F.; Santoro, D.; Arena, U. Waste Manage. Res. 2014, 32, 323-330.

(20) Scala, F.; Chirone, R. Biomass Bioenergy 2008, 32, 252-266.

(21) Zevenhoven-Onderwater, M.; Backman, R.; Skrifvars, B.-J.; Hupa, M. Fuel 2001, 80, 1489-1502.

(22) Billen, P.; Costa, J.; Van Der Aa, L.; Westdorp, L.; Van Caneghem, J.; Vandecasteele, C. Energy Fuels 2014, 28, 5455-5462.

(23) Barišić, V.; Åmand, L.-E.; Zabetta, E. C. The role of limestone preventing the agglomeration and slagging during CFB combustion of high-phosphorous fuels. World Bioenergy, Jönköping (Sweden), May 27-29, 2008.

(24) Fryda, L.; Panopoulos, K.; Kakaras, E. Powder Technol. 2008, $181,307-320$.

(25) Walawender, W.; Ganesan, S.; Fan, L.; et al. In Symposium Papers. Energy from Biomass and Wastes V. Lake Buena Vista, Florida, January 26-30, 1981; 1981; pp 517-527.

(26) Wen, C.; Yu, Y. AIChE J. 1966, 12, 610-612. 
(27) van Paasen, S.; Cieplik, M.; Phokawat, N. Energy Research Centre of the Netherlands (ECN): Petten, Netherlands, 2006.

(28) Osipovs, S. Int. J. Environ. Anal. Chem. 2009, 89, 871-880.

(29) Padban, N.; Wang, W.; Ye, Z.; Bjerle, I.; Odenbrand, I. Energy Fuels 2000, 14, 603-611.

(30) Kinoshita, C.; Wang, Y.; Zhou, J. J. Anal. Appl. Pyrolysis 1994, 29, 169-181.

(31) Siedlecki, M.; De Jong, W.; Verkooijen, A. H. M. Energies 2011, 4, 389-434.

(32) Devi, L.; Ptasinski, K. J.; Janssen, F. J. Biomass Bioenergy 2003, 24, $125-140$.

(33) Gómez-Barea, A.; Campoy, M.; Ollero, P.; Fernández-Pereira, C. In 19th International Conference on Fluidised Bed Combustion; 2006; pp 21-24.

(34) Piotrowska, P.; Zevenhoven, M.; Davidsson, K.; Hupa, M.; Åmand, L.-E.; Barišić, V.; Coda Zabetta, E. Energy Fuels 2010, 24, $4193-4205$.

(35) Fernández Llorente, M.; Escalada Cuadrado, R.; Murillo Laplaza, J.; Carrasco García, J. Fuel 2006, 85, 2081-2092.

(36) Kumar, A.; Eskridge, K.; Jones, D. D.; Hanna, M. A. Bioresour. Technol. 2009, 100, 2062-2068.

(37) Turn, S.; Kinoshita, C.; Zhang, Z.; Ishimura, D.; Zhou, J. Int. J. Hydrogen Energy 1998, 23, 641-648.

(38) Zhou, J.; Masutani, S. M.; Ishimura, D. M.; Turn, S. Q.; Kinoshita, C. M. Ind. Eng. Chem. Res. 2000, 39, 626-634.

(39) Hanping, C.; Bin, L.; Haiping, Y.; Guolai, Y.; Shihong, Z. Energy Fuels 2008, 22, 3493-3498.

(40) Gómez-Barea, A.; Ollero, P.; Leckner, B. Fuel 2013, 103, 42-52.

(41) Narvaez, I.; Orio, A.; Aznar, M. P.; Corella, J. Ind. Eng. Chem. Res. 1996, 35, 2110-2120.

(42) Wang, Y.; Kinoshita, C. Sol. Energy 1992, 49, 153-158.

(43) Meng, X.; De Jong, W.; Verkooijen, A. H. M. 17th European Biomass Conference and Exhibition, Germany, Hamburg, 2009, 940947. 
